\title{
Reforming of ethanol in a microwave surface-wave plasma discharge
}

\author{
A. Yanguas-Gil, J. L. Hueso, J. Cotrino, A. Caballero, and A. R. González-Elipe ${ }^{a)}$ \\ Instituto de Ciencia de Materiales de Sevilla and Dptos. de Física Atómica, Molecular y Nuclear \\ and Química Inorgánica (CSIC-Universidad de Sevilla)
}

(Received 22 March 2004; accepted 1 September 2004)

\begin{abstract}
Hydrogen production through plasma reforming of ethanol at room temperature and moderate pressure has been carried out in a microwave surface-wave reactor. Both pure ethanol and mixtures ethanol-water have been studied. The reforming yield was almost $100 \%$ in all conditions with $\mathrm{H}_{2}$, solid carbon, $\mathrm{CO}$ and $\mathrm{CO}_{2}$ as the main reaction products. In the mixture ethanol-water the formation of solid $\mathrm{C}$ was avoided. The optical emission spectroscopy analysis has shown that the formation of the excited species $\mathrm{CO}^{*}, \mathrm{CH}^{*}$ and $\mathrm{C}_{2}^{*}$ depends on the plasma mixture. The temperature of the $\mathrm{OH}^{*}$ species was determined by analyzing the shape profile of its emission band. (C) 2004 American Institute of Physics. [DOI: 10.1063/1.1808875]
\end{abstract}

Hydrogen is being considered as a strategic fuel for the future and, consequently, the development of procedures for its production is nowadays deserving much effort. ${ }^{1,2}$ At present, two major technologies are being used for obtaining this fuel at large scale: the catalytic route through the water gas shift reaction and the electrolytic decomposition of water. In both cases the produced $\mathrm{H}_{2}$ cannot be considered as a renewable fuel since it is obtained from another primary energy source. The present work reports on the feasibility of producing $\mathrm{H}_{2}$ from ethanol by plasma reforming. Ethanol is a liquid fuel that can be obtained from the biomass and, in this regard, can be considered as renewable.

Plasma procedures have been used in the past for the reforming of methane and other hydrocarbons. Depending on the type of excitation (microwave, dielectric barrier discharge, etc.) it has been reported that plasma reforming of methane yields $\mathrm{C} 2$ or higher hydrocarbons ${ }^{3}$ and, in some cases, $\mathrm{H}_{2}$ as products of the reaction. ${ }^{4}$ A problem with the direct reforming of $\mathrm{CH}_{4}$ into $\mathrm{C}$ and $\mathrm{H}_{2}$ is that this reaction is endothermic at room temperature. Therefore, for its practical implementation it is necessary either to heat the hydrocarbon at higher temperatures or to treat mixtures of methane (or other hydrocarbons) and $\mathrm{H}_{2} \mathrm{O}$ simulating the water gas shift reaction. Successful attempts combining both types of approaches have been reported. Thus, Etievant and Roshl ${ }^{2}$ have shown that hydrocarbon (particularly $\mathrm{CH}_{4}$ ) and/or alcohols are efficiently reformed by dc or microwave (MW) plasmas when mixtures of these gases are mixed with steam and heated at temperatures higher than $473 \mathrm{~K}$.

In the present work, the feasibility of the hydrogen obtention through reforming of ethanol and mixtures of ethanol plus water is studied in a MW surface-wave (SW) plasma device at room temperature. This plasma ignition procedure has been used for other applications including thin film deposition $^{5}$ or removal of volatile organic compounds. ${ }^{6}$

The microwave discharge is generated in a quartz tube of $1.5 \mathrm{~mm}$ of inner radius. A SW launcher (Surfatron ${ }^{7}$ ) transforms the electromagnetic power from the microwave generator into a traveling wave that propagates along the dielectric tube, creating the plasma inside it. Three different mixtures have been used: pure ethanol $(0.02 \mathrm{~mol} / \mathrm{h}, 3$ Torr $)$,

\footnotetext{
a) Author to whom correspondence should be addressed; electronic mail: arge@icmse.csic.es
}

mixture ethanol-water $(0.02 \mathrm{~mol} / \mathrm{h}, 0.06 \mathrm{~mol} / \mathrm{h}, 10$ Torr $)$ and pure water $(0.06 \mathrm{~mol} / \mathrm{h}, 10$ Torr $)$. Vapors were dosed from liquid ampoules using calibrated mass flow controllers. The electromagnetic power used ranged between 20 and $80 \mathrm{~W}$, although most experiments were done with a power of $60 \mathrm{~W}$. Composition of the reaction mixture was determined by mass spectrometry (Balzers Pfeiffer QMS422 mass spectrometer) after calibration of the intensity of peaks with mixtures of known composition. The emission spectrum of the discharge was analyzed by optical emission spectroscopy (OES) using a Jobin-Yvon HR250 monochromator and a Hamamatsu photomultiplier tube. A scheme of the experimental setup is presented in Fig. 1.

Mass spectrometry showed a strong decrease of the $\mathrm{CH}_{3} \mathrm{CH}_{2} \mathrm{OH}$ peaks revealing almost $100 \%$ of ethanol decomposition. Simultaneously peaks of $\mathrm{H}_{2}, \mathrm{CO}$ and $\mathrm{CO}_{2}$ developed, indicating a net production of these gases. A quantitative evaluation of the reaction products is included in Table I. Besides $\mathrm{CO}, \mathrm{CO}_{2}$ and $\mathrm{H}_{2}$, which are the main reaction products of the plasma process, some $\mathrm{C} 2$ or higher hydrocarbons are detected as traces in the case of pure ethanol. Under these conditions a deposit of solid carbon was also formed in the inner walls of the quartz tube. This solid carbon became hot red and was deleterious for the plasma, which extinguished when a critical mass of carbon was formed. With the waterethanol mixture the formation of the solid carbon was avoided while keeping a high yield of $\mathrm{H}_{2}$. In both cases the composition of the final mixture was not affected by the incident power in the studied range, from 20 to $80 \mathrm{~W}$.

Although the gas mixtures were not externally heated, an increase of their temperature was detected as a result of the plasma discharge. According to the model proposed by Moisan, ${ }^{8}$ in a low pressure surface-wave discharge the microwave power is absorbed mainly by the electrons, which

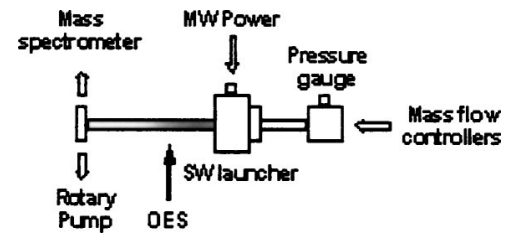

FIG. 1. Schematic plot of the experimental setup used for the reforming of ethanol and mixtures of ethanol plus water. 
TABLE I. Percentages of the different carbon compounds detected as products during the plasma microwave reforming of ethanol (Solid $\mathrm{C}$ was determined as the difference of the decomposed ethanol and the formed $\mathrm{CO}$ and $\mathrm{CO}_{2}$ ).

\begin{tabular}{cccc}
\hline \hline \% Detected & Ethanol $60 \mathrm{~W}$ & $\mathrm{EtOH}+$ Water $60 \mathrm{~W}$ & EtOH+Water $80 \mathrm{~W}$ \\
\hline $\mathrm{CO}$ & 55 & 95 & 95 \\
$\mathrm{CO}_{2}$ & $<1$ & 5 & 5 \\
$\mathrm{C}$ deposit & 45 & $\ldots$ & $\ldots$ \\
$\mathrm{C}_{x} \mathrm{H}_{y}, x>2$ & Traces & $\ldots$ & $\ldots$ \\
$\mathrm{C}_{x} \mathrm{H}_{y}, x=1,2$ & Traces & Traces & Traces \\
\hline \hline
\end{tabular}

partially lose their excess energy through collisions with the gas molecules and atoms, thus increasing their temperature. The temperature of the external wall of the quartz tube provides a lower limit of this magnitude and it was measured using a thermocouple at different axial positions. For a pure ethanol discharge this value ranged between 500 and $700 \mathrm{~K}$, increasing with the incident power.

According to the data in Table I, and disregarding the minority products, the global plasma reactions for pure ethanol and the water-ethanol mixture can be described according to

$$
\begin{aligned}
& \mathrm{CH}_{3} \mathrm{CH}_{2} \mathrm{OH} \rightarrow \mathrm{C}+\mathrm{CO}+3 \mathrm{H}_{2}, \\
& \mathrm{CH}_{3} \mathrm{CH}_{2} \mathrm{OH}+\mathrm{H}_{2} \mathrm{O} \rightarrow 2 \mathrm{CO}+4 \mathrm{H}_{2} .
\end{aligned}
$$

A similar experiment carried out with pure water also led to the almost total splitting of water according to the reaction $\mathrm{H}_{2} \mathrm{O} \rightarrow \mathrm{H}_{2}+1 / 2 \mathrm{O}_{2}$.

The light produced in the glow zone was characterized by OES. Figure 2 shows the recorded spectra corresponding to the three vapor compositions: ethanol, ethanol-water and pure water. By comparison with reported spectra ${ }^{9}$ the different bands observed in this figure have been identified in Table II. According to the assignment in this table the spectrum of the ethanol plasma is characterized by bands and lines due to $\mathrm{CO}^{*}, \mathrm{OH}^{*}$ and $\mathrm{H}^{*}$ species, together with some smaller bands due to $\mathrm{CH}^{*}$ and $\mathrm{C}_{2}^{*}$ species. For the mixture ethanol plus water the spectrum is dominated by the lines of the Balmer series of hydrogen $\left(\mathrm{H}_{\alpha}, \mathrm{H}_{\beta}, \mathrm{H}_{\gamma}\right)$ and by the 3064 system of the $\mathrm{OH}^{*}$ species. Some minority contribution of $\mathrm{CO}^{*}$ and $\mathrm{CH}^{*}$ species can be also detected in this spectrum. Except for the absence of these latter bands, the spectrum of water plasma resembles that of the mixture of ethanol plus water with the addition of some peaks due to atomic oxygen. The appearance in the plasma of pure ethanol of intermediate species of the type $\mathrm{C}_{2}^{*}$ and $\mathrm{CH}^{*}$ can be taken as an indication of the formation of, respectively, solid carbon and higher

TABLE II. Main features of OES spectra.

\begin{tabular}{llll}
\hline \hline Species & System & Transition & Position $(\mathrm{nm})$ \\
\hline $\mathrm{C}_{2}$ & Swan & ${ }^{3} P \rightarrow{ }^{3} P$, ground state & $450-500$ \\
$\mathrm{CH}$ & 4300 A & ${ }^{2} D \rightarrow{ }^{2} P$, ground state & 430 \\
& 3900 A & ${ }^{2} S \rightarrow{ }^{2} P$, ground state & 390 \\
& 3143 A & ${ }^{2} S \rightarrow{ }^{2} P$, ground state & 314 \\
$\mathrm{CO}$ & 4th Positive & $A^{1} P \rightarrow X^{1} S$, ground state & $200-280$ \\
& 3rd Positive and $5 \mathrm{~B}$ & $b^{3} S \rightarrow a^{3} P$ & $150-300$ \\
$\mathrm{OH}$ & 3064 A & ${ }^{2} S \rightarrow{ }^{2} P$, ground state & 295,306 \\
$\mathrm{H}$ & Balmer series & $n \rightarrow 2 s, 2 p$ & $656,486,434,410$
\end{tabular}
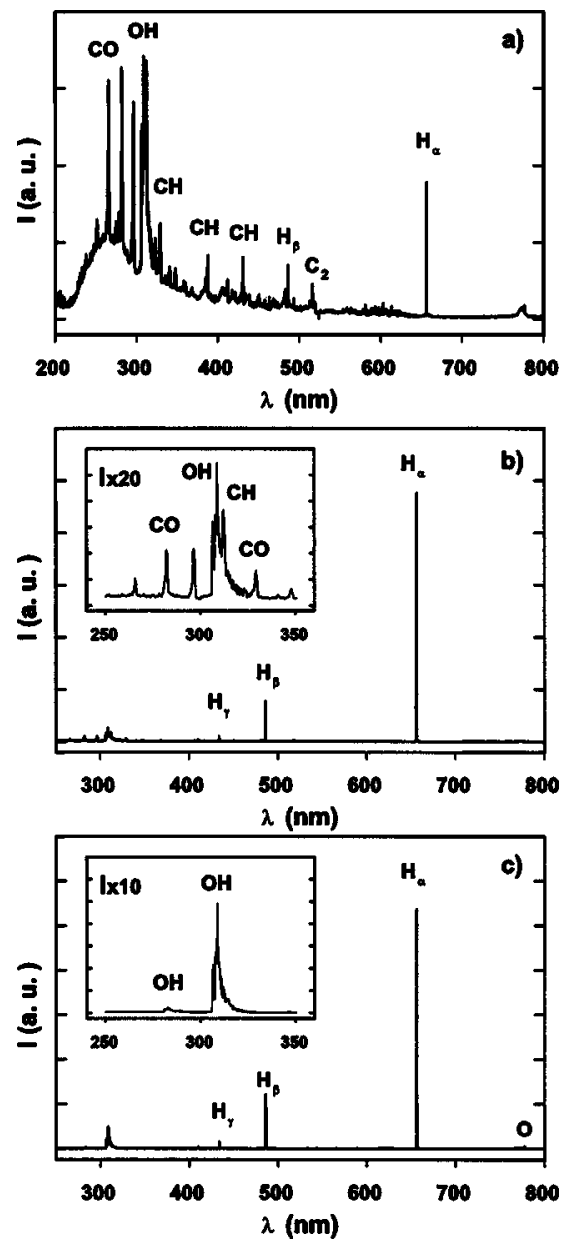

FIG. 2. OES spectra of plasma discharges: (a) pure ethanol, (b) ethanol/ water and (c) pure water. The inset figures show the spectral range between 250 and $350 \mathrm{~nm}$ in more detail.

hydrocarbons, as these species are typically found as intermediate radicals in the formation mechanism of these products. ${ }^{3}$

The rotational temperature of the $\mathrm{OH}$ molecule was estimated by fitting the emission band of the $\mathrm{OH}^{*}$ system located between 306 and $314 \mathrm{~nm}$. The fitting procedure has been discussed in different publications. ${ }^{10,11}$ These calculations yield the rotational temperatures summarized in Table III for the three reactions considered and $60 \mathrm{~W}$ of exciting power. The data reveal that the rotational temperature of $\mathrm{OH}$ increases greatly from water to the ethanol plasma. Calculations of $\mathrm{OH}$ rotational temperature as a function of power showed that this parameter increased almost linearly with the power, ranging from $1150 \mathrm{~K}$ at $30 \mathrm{~W}$ to $1300 \mathrm{~K}$ at $60 \mathrm{~W}$ for pure water. Similar linear variations were found for pure ethanol and the mixture of ethanol-water. This temperature cannot be identified with the gas temperature since the rotational modes at low pressures may have a higher temperature than the vibrational and translational modes. ${ }^{12}$

TABLE III. Calculated $\mathrm{OH}^{*}$ rotational temperatures.

\begin{tabular}{cc}
\hline \hline Reaction mixture, 60 W & $T_{R}(\mathrm{~K})$ \\
\hline Ethanol & $>2500$ \\
Ethanol+water & 1600 \\
Water & 1300 \\
\hline
\end{tabular}


The increase in the average rotational temperature of $\mathrm{OH}^{*}$ species as the overall ratio $\mathrm{C} / \mathrm{O}$ in the discharge increases (i.e., for mixtures $\mathrm{CH}_{3} \mathrm{CH}_{2} \mathrm{OH}+\mathrm{H}_{2} \mathrm{O}$ and, particularly, pure ethanol) can be related to the dissociation energies of the different intermediate species detected in the discharge. Thus, while the value of the dissociation energies of $\mathrm{C}_{2}, \mathrm{CH}$ and $\mathrm{CO}$ species are 6.2, 3.46 and $11.09 \mathrm{eV}$, respectively, that of $\mathrm{OH}$ is $4.39 \mathrm{eV} .{ }^{13}$ Therefore, the formation and posterior decomposition of diatomic species such as $\mathrm{CO} *$ and $\mathrm{C}_{2}^{*}$ implies the release of more energy, which is distributed by excitation exchange from the vibrational and rotational modes of $\mathrm{CO}$ and $\mathrm{C}_{2}$ to the rest of the species of the plasma and, in particular, to the $\mathrm{OH}^{*}$. Moreover, for the same gas temperature, the free energy and therefore the enthalpy of reaction (1) is greater than that of reaction (2) (i.e., $-100 \mathrm{~kJ} / \mathrm{mol}$ and $-70 \mathrm{~kJ} / \mathrm{mol}$ at $700 \mathrm{~K}),{ }^{14}$ so that for plasmas of pure ethanol more energy is released. This excess of energy is absorbed by other molecules, yielding higher temperatures and higher excitation degrees in the pure ethanol discharge.

The reaction schemes presented below, compatible with reported reaction kinetics, ${ }^{15}$ account for both the reaction products and the intermediate species detected by OES.

$$
\begin{aligned}
& \mathrm{CH}_{3} \mathrm{CH}_{2} \mathrm{OH} \underset{\begin{array}{c}
\text { electron } \\
\text { impact }
\end{array}}{\stackrel{\mathrm{H}_{2}}{\longrightarrow}} \mathrm{CH}_{2} \mathrm{OH}, \mathrm{CH}_{3} \underset{\begin{array}{c}
\text { e,radical } \\
\text { impact }
\end{array}}{\stackrel{\uparrow}{\longrightarrow}} \mathrm{CO} *, \mathrm{C}_{2}{ }^{*} \underset{\begin{array}{c}
\text { carbon } \\
\text { condensation }
\end{array}}{\longrightarrow} \mathrm{C}(\text { solid), } \mathrm{CO} \text {, } \\
& \left.\begin{array}{ccc}
\mathrm{CH}_{3} \mathrm{CH}_{2} \mathrm{OH} & \stackrel{\mathrm{H}_{2}}{\uparrow} & \\
& \stackrel{\uparrow}{\text { e impact }} & \mathrm{CH}_{2} \mathrm{OH}, \mathrm{CH}_{3} \\
\mathrm{H}_{2} \mathrm{O} & \underset{\text { e impact }}{\longrightarrow} & \mathrm{H}^{*}, \mathrm{O}^{*}
\end{array}\right\} \rightarrow \mathrm{H}_{2}, \mathrm{CO} .
\end{aligned}
$$

The reaction scheme (3) corresponds to the reforming of ethanol. It indicates that atomic hydrogen is removed from ethanol, and eventually the $\mathrm{C}-\mathrm{C}$ bond dissociated, by direct electron impact. This process continues for the intermediate species and leads to the formation of $\mathrm{H}_{2}$. Some of these intermediate species such as $\mathrm{CH}^{*}$ have been detected by OES [cf. Fig. 2(a)]. Further hydrogen removal by electron and radicals impact leads to the formation of $\mathrm{CO}^{*}$ and $\mathrm{C}_{2}^{*}$ species [cf. Fig. 2(a)], this latter being considered a precursor of the formation of solid carbon.

The reaction scheme (4) accounts for the processes that take place in mixtures of ethanol plus water. The process can be considered as equivalent except for the excess of oxygen radicals in the plasma, coming from the splitting of the water molecules, that prevent the formation of $\mathrm{C}_{2}^{*}$ radicals and therefore the production of solid carbon.

The previous results show that almost $100 \%$ reforming of ethanol can be achieved by plasma decomposition in a SW device by working at moderate pressure and room temperature. In most works dealing with the plasma reforming of hydrocarbons at room temperature, higher hydrocarbons rather than $\mathrm{H}_{2}$ are obtained as main reaction products. By contrast, plasma decomposition of ethanol, according to reaction (1), is thermodynamically favored at room temperature and has a very negative value of free energy at a temperature close to that measured at the walls of the plasma tube (i.e., $\delta G=-100 \mathrm{~kJ} / \mathrm{mol}$ at $700 \mathrm{~K}$ ). The presence of an oxygen atom in the ethanol molecule and the negative energy of formation of $\mathrm{CO}$ are the driving forces that favor the plasma decomposition reaction of ethanol at room temperature.

The authors thank the Ministerio de Ciencia y Tecnología for financial support (projects PPQ2001-3108 and FIT 120300-2003-14, this latter in collaboration with Instalaciones ABENGOA, S. A.).

${ }^{1}$ G. A. Deluga, J. R. Salge, and L. D. Schmidt et al., Science 303, 993 (2004).

${ }^{2}$ C. Etievant and M. Roshl, US Patent No. 6,245,309 B1 (2001).

${ }^{3}$ M. Heintze, M. Magureanu, and M. Kettlitz, J. Appl. Phys. 92, 7022 (2002).

${ }^{4}$ M. Deminski, V. Jivolov, and B. Potapkin et al., Pure Appl. Chem. 74, 413 (2002).

${ }^{5}$ C. F. M. Borges, V. T. Airoldi, E. J. Corat, M. Moisan, S. Schelz, and D. Guay, J. Appl. Phys. 80, 6013 (1996).

${ }^{6}$ J. Arno, J. W. Bevan, and M. Moisan, Environ. Sci. Technol. 30, 2427 (1996).

${ }^{7}$ M. Moisan, C. Barbeau, R. Claude, C. M. Ferreira, J. Margot, J. Paraszczak, A. B. Sa, G. Sauv, and M. R. Wertheimer, J. Vac. Sci. Technol. B 9, 8 (1991).

${ }^{8}$ M. Moisan and J. Pelletier, Microwave Excited Plasmas (Elsevier, New York, 1992).

${ }^{9}$ R. W. B. Pearse and A. G. Gaydon, The Identification of Molecular Spectra (Chapman and Hall, London, 1950).

${ }^{10}$ C. de Izarra, J. Phys. D 33, 1697 (2000).

${ }^{11}$ H. M. Dieke and H. M. Crosswhite, J. Quant. Spectrosc. Radiat. Transf. 2, 97 (1962).

${ }^{12}$ M. Capitelli, C. M. Ferreira, B. F. Gordiets, and A. I. Osipov, Plasma Kinetics in Atmospheric Gases (Springer, Berlin, 2000).

${ }^{13}$ A. A. Radzig and B. M. Smirnov, Reference Data on Atoms, Molecules and Ions (Springer, Berlin, 1985).

${ }^{14}$ D. R. Lide, Handbook of Chemistry \& Physics, 84 ed. (CRC, Boca Raton, FL, 2003).

${ }^{15}$ D. L. Baulch et al., J. Phys. Chem. Ref. Data 21, 411 (1992). 